Victoria Dunaeva, 2020

Volume 6 Issue 2, pp. 436-443

Date of Publication: 31st August, 2020

DOI- https://doi.org/10.20319/pijss.2020.62.436443

This paper can be cited as: Dunaeva, V., (2020). Women and Men in Midlife Crisis. PEOPLE: International Journal of Social Sciences, 6(2), 436-443.

This work is licensed under the Creative Commons Attribution-NonCommercial 4.0 International License. To view a copy of this license, visit http://creativecommons.org/licenses/by-nc/4.0/ or send a letter to Creative Commons, PO Box 1866, Mountain View, CA 94042, USA.

\title{
WOMEN AND MEN IN MIDLIFE CRISIS
}

\author{
Victoria Dunaeva \\ Activus Aspectus. Innovative Laboratory, Warsaw, Poland \\ vdunaeva@yahoo.com
}

\begin{abstract}
Uncomfortable period, which men and women experience between the age of 35 and 55, psychologists define as a midlife crisis. At that period some people are getting anxious and loose the nerves over a small issue. They consider it a kind of depression. For them, this period is a true "crisis" and they question every choice they've made during the first half of their life and look back on it with remorse and regret. They are struggling with their mortality, confidence, identity, and accomplishments thus far in life. Negative emotions often evoke them to start radical changes to their current lifestyle. Sometimes they change their life for a better, sometimes they make big mistakes. In my presentation, I would like to take a psychological look at this issue and pay special attention to the differences in experiencing a midlife crisis by women and men. I am also going to define reasons that may lead to this emotional crisis.
\end{abstract}

\section{Keywords}

Midlife Crisis, Self-Esteem, Clinical Psychology, Self-Realization

\section{Introduction}

The term of midlife crisis appeared in 1965 and described the crisis of self-identity and self-confidence that many people experienced around mid-age.

Elliot Jaques, Canadian psychoanalyst, and management consultant were the first who paid attention to this psychological phenomenon. He described it in the article "Death and the midlife crisis" published in the International Journal of Psycho-Analysis (Jaques, 2001). 
The concept of midlife crisis becomes in the center of the interest of many psychologists and psychoanalysts. As Candice L. Shelby stresses, one result of disenchantment of the world, the replacement of the belief in spiritual beings, absolute moral truth, and a just God with a naturalistic understanding of our existence and meaning-making, has been widespread existential insecurity (Shelby, 2019). Feeling of insecurity evokes an emotional crisis.

German-American psychoanalyst Karen Horney, discovering the nature of neurosis, defined the specific character of midlife emotional problems (Horney, 1991). With comparison to neurosis, a mild life crisis has the potential for the healthy growth of a person. Horney called that process of growth self-realization, which she described as the development of a person's given possibilities.

Famous psychoanalyst Carl Jung defined 5 main phases of midlife transition:

- Accommodation - in other words, meeting other's expectations

- Separation - rejecting the self

- Liminality - state of uncertainty and disorientation

- Reintegration - understanding "who is my true self" and feeling being comfortable with it

- Individuation - accepting the negative, undesirable aspects of their character (Jung, 2010).

It should be mentioned that Carl Jung suffered his midlife crisis, between the ages of thirty-nine to forty-five. He described his long-term struggle with his crisis in his Red Book (Jung, 2009). Being a famous psychiatrist and psychotherapist, he even thought about the commitment of suicide. Basing on his own experience, Jung concluded that successful life means balance, wholeness. If we make a lot of effort in one direction, our unconsciousness would compensate for this inequality (for instance, by horror dreams, insomnia, compulsive eating, obsessive thoughts, fatigue, low emotional state, etc). Symbolically, when Jung emerged from his period of crisis, he made the most important contributions to psychology including concept about collective unconsciousness common to all human beings.

Another famous psychoanalyst Erick Erickson wrote about the mid-life crisis as very important for finding opportunities to make adjustments in their lives that will lead to greater fulfillment (Erickson, 2017). He also noted the big influence of this process transition on the well-being of people. It can be especially painful for those people who felt that they made mistakes and wasted their time and that they didn't time anymore to make necessary changes. 
According to the contemporary American Psychological Association, midlife crises often share similar traits with deep depression. However, we should remember that the midlife crisis is the process of a transition of identity that can happen with middle-aged individuals, from about 35 to 55 years old.

James Hollis, one of the leading contemporary psychoanalysts claims that "in the second half of life, the questions suddenly appear: 'Who I am, apart from the roles I have to play? What does my soul ask for? Can I have the courage to shift my course and loss the collective approval?' "(Hollis, 1993)" To understand the meaning of this process we need to separate ourselves emotionally from society - Hollis believes. "We are not here to fit in, be well balanced, or provide an example for others. We are here to be eccentric, different, perhaps strange, perhaps merely to add our small piece, our little clunky, chunky selves, to the great mosaic of being. As the gods intended, we are here to become more and more ourselves." -he said in the book What Matters Most: Living a More Considered Life (Hollis, 2008).

How I define in my practice as a clinical psychologist that somebody is suffering exactly from a midlife crisis? Sometimes it is difficult to be sure if we deal with such a deep crisis or reason for suffering is just related to inappropriate life conditions (crisis in relationships with a partner, problems at workplace, communication conflicts with adult children, etc.). In my definition, the midlife crisis has always conflicts in many significant aspects of life. I notice that most of the people experiencing midlife crisis blame and shame one so strongly that they don't allow themselves to see solutions for their problems. They look like very traumatized and tend to see danger everywhere. It isn't easy to involve them with the process of psychotherapy because they are often suspicious, skeptical, and cruel to oneself and other people around them. Now I propose you look at signs of midlife crisis describing in traditional clinical psychology.

\section{The Signs of Midlife Crisis}

The midlife crisis manifests itself on the surface of consciousness in many aspects: pressure to change job, career failure; addictions, divorce, loss of sense; etc. No one is immune to this transition process: rich and middle-class people, women and men, welleducated and simple farmers. Radical changes may touch everybody who hasn't answered all the important questions and haven't felt satisfaction at midlife age.

Midlife crises have several specific symptoms. The main sign is loosing of sense of existence related to belief in own low-esteem and total injustice of life. People start asking 
themselves deeply; rhetoric questions about the sense of all efforts they have made to achieve some position at job, society. They begin to look at their own family differently, finding mostly negative signs. They suddenly stop feeling satisfaction in almost all aspects of their life. Making any decisions (concerning job or family) becomes difficult for them; they cannot concentrate on important issues and feel deep apathy. Sometimes it seems to them that the only solution is to end with everything and start again. They begin to think about the change of job, profession, partner of life. They often feel being used by others. They try to find reply to self-critical thoughts, but they often feel powerless, - Paul Gilbert, author of books about self-esteem notes (Gilbert, 2012).

One of the signs of midlife crises can be jealousy to other people and their successes. Achievements of others seem to be unjust. People begin to compare themselves to others and suffer from "wrong using of own abilities" and from lost opportunities for success.

Gaining or losing weight (without any serious problem with health) can be also a symptom of Midlife crises, according to the American Psychological Association. Any problems with weight are always related to a problem with self-acceptance. Lack of physical power and physical pain appear during any deep emotional crisis. Headaches, gastrointestinal issues, muscle pain, and tension are frequent complaints of people overcoming mid-life transition.

Many people begin to blame their marriage for unhappiness. They isolate themselves emotionally from other members of the family and lose interest to them. Sometimes they make an impulsive decision about divorce or separation. Problems with sleeping, long-term anxiety, and panic attacks only re-enforce that kind of emotional conflict.

One of the typical signs of that kind of emotional crisis is a dismal vision of the future. Dreams don't come true, opportunities seem to be lost, and life becomes short People feel deep remorse for their goals that have not been accomplished. They don't understand how to live without any goals and dreams and see the future in a pessimistic way.

Midlife crises don't happen with everybody. According to Melanie Fennell, low self-esteem causes distress and disruption in a person's life and lead to feelings of incompetence and inadequacy (Fenell, 2016).

Research has shown that low esteem - lasting negative beliefs about the self - may contribute towards a range of difficulties, which stay invisible for a person for a long time. Root problems are related to childhood or adolescence of people. Our idea of ourselves may be a result of how we were treated early in life. If children were not be accepted by parents and adults, they often assume that this reflects something bad in them. If they were 
systematically criticized or punished, this experience will leave many psychological scars. People who are self-important and have a positive belief about themselves are more prepared for ups and downs.

\section{Conclusion}

If there is any difference between women and men experiencing a midlife crisis? Yes and no. Women often overcome that crisis in a more balanced way. They apply to psychotherapists more often than men and try to understand themselves without any impulsive decision or radical changes in life. Working on traumatic memories, women discover unconscious emotions and strong body reactions. In this context, they may reveal the connection between their thoughts, emotions, and old memories. This associative process showing the interaction between mind and body may liberate them from negative emotions. After psychological therapy, sometimes women also decide to divorce, but after many attempts to return emotional closeness into a relationship. With comparison to men, after the divorce, they don't' try to find another partner quickly and learn to enjoy life and themselves. Men experiencing midlife crisis feel strong remorse about unfulfilled carrier goals and lack of financial success. They are known to buy expensive sports cars or motorcycles, trying to compensate for lack of self-confidence at that period. Women feel more unsatisfied with their role in the family, lack of romantics in relations with a partner, lack of respect from adult children. One day they found that they live under strong pressure of unexpressed feelings, wishes, and regrets. In this case, it is important to discover what was the first reason for emotional closing and fear of revealing oneself, what was the most traumatic experience in childhood for that person.

A true midlife crisis usually involves changing your entire life in a hurry, says Calvin Colarusso, a clinical professor of psychiatry (Colarusso, 2006). According to him, especially men feel a strong pressing need to make changes in their life and at that moment they completely don't think about the consequences of their actions, because only changes make meaning for them. In my opinion, in contemporary world women and men go through a midlife crisis in a similar way, analyzing what could be causing their unhappiness and trying to change it. Earlier women were more limited by financial conditions and public opinion. It was always a difficult decision for them to conduct radical changes in their life and their attempts to improve their well-being often finished with psychological support which alleviates their emotional suffering. Women considered that they couldn't ensure their children with life on the appropriate level and they just rejected their dreams and emotional 
needs. According to my observation, nowadays the situation is changing and most of the women are eager to be financially independent to have more life choices.

Losing interest in life-related to midlife crisis borders on self-sabotage. Depression, anxiety, fatigue syndrome often limit us to believe in ourselves and to find another approach to solving problems seems to be intractable. Dalai Lama said that "we only have ourselves to blame" (Lama, 2011). I would add that we only have ourselves to blame, forgive, accept, and love. A midlife crisis can be an excellent opportunity for creating healthy self-esteem. The significant condition for recovery is to discover our hidden emotional conflicts and free one from them. Each of us has the potential for self-recovery; the main task is to access our inner resources. When we are self-aware and know what we want - we always have a chance to change our life. Or we can change our expectations from life and from others that often reflect our negative beliefs about the self.

Shirley Maclaine, the writer, and spiritual teacher, describes frankly own process transition in the book "Going within" (Maclaine, 2002). She said in the introduction that she "was shifting from feeling of helplessness to a position that recognizes the power within.

That doesn't mean that midlife crisis should lead us to "cult of self", self-centering position in our relationships with others. The happier we are individual, the more inspiration and motivation we have for better work and a better understanding of our surroundings.

As Carl Jung said, "Your vision will become clear only when you can look into your own heart" (Jung, 2009).

Confident people create a cycle of influence where they are thinking about what they can do (and what they want to do). We should also understand that for our well-being we need to have compassion in attitude to ourselves. Recent studies in human sciences have shown how compassion qualities of the mind influence our brains, bodies, health, and social relations (Lee, 2012). Compassion and confidence are especially significant when we are stressed and disoriented and feel helpless experiencing a midlife crisis. At that moment most of us don't accept the "old version" of one, feeling completely lost. Compassion towards oneself helps to believe in the possibility to create a "new version" of one, even if we change only several things in our life. The most important is our awareness of our own emotional needs and our efforts to ensure them. If we try, we are not lost. That's why in my practice as a clinical psychologist I propose my clients to make the following exercise. I ask them to answer the questions: how I would like to think about myself? How I would like to behave towards myself when I feel stressed? What things are the most important for my life? After that exercise, I notice that many clients start to understand that living in the process which 
requires a lot of effort and attention. This is the reason to respect oneself for each attempt to change something even if we were mistaken. I completely agree with my colleagues who believe that a compassion mind is capable to resolve any problem (Harman, Lee, and Barker, 2010).

Begin with self and do it with acceptance and love.

\section{REFERENCES}

Colarusso, C. (2006). The Absence of a Future: The Effect of Past Experience and Current Developmental Conflicts on a Midlife Analysis. Journal of the American Psychoanalytic Association, 54 (3), 29-43. https://doi.org/10.1177/00030651060540030501

Erickson, E. (2017). Before You Wake: Life Lessons from a Father to His Children. Paris: Hachette Books.

Fenell, M. (2016). Overcoming Low Self-Esteem, 2nd Edition: A self-help guide using cognitive behavioral techniques. London: Robinson.

Gilbert, P. (2012). The Compassionate Mind. London: Robinson

Hollis, J. (1993). The Middle Passage: From Misery to Meaning in Middle-Life. Toronto: Inner City Books

Harman, R., Barker, C \& Lee, D. (2010). The role of shame and self-critical thinking in the development and maintenance of current threat in post-traumatic stress disorder. Clinical Psychology \& Psychotherapy, 17(1), 13-24. https://doi.org/10.1002/cpp.636

Hollis, J. (2008). What Matters Most: Living a More Considered Life. Hollywood: Gotham Books.

Horney, K. (1991). Neurosis in Human Growth. New York: W. Norton Company.

Jaques, E. (2001). The Life and Behavior of Living Organisms: A General Theory. London: Praeger.

Jung, C. (2010). 'The Undiscovered Self: With Symbols and the Interpretation of Dreams. New Jersey: Princeton University. https://doi.org/10.1515/9781400839179

Jung, C. (2009). The Red Book: London: Liber Novus. Norton.

Lama D. (2011). Beyond Religion: Ethics for a Whole World. London: Houghton Mifflin Harcourt.

Lee, D. (2012). The Compassion Mind Approach to Recovering From Trauma. London: Robinson. 
PEOPLE: International Journal of Social Sciences

ISSN 2454-5899

Maclain, S. (2002). Going within. A Guide for Inner Transformation. New York: Bantam Books.

Shelby, C. (2019). What Kind of Healing Does Psychedelic-assisted Psychotherapy Foster? PEOPLE: International Journal of Social Sciences, 5 (3), 01-11. https://doi.org/10.20319/pijss.2019.53.0111 